\title{
Sistem Informasi Kepegawaian Daerah Pada Badan Kepegawaian, Pendidikan dan Pelatihan Kabupaten Musi Rawas Berbasis Web
}

\author{
Joni Karman \\ STMIK Musirawas Lubuklinggau, Jln. Jend Besar H.M. Soeharto \\ Kel. Lubuk Kupang Kec. Lubuklinggau Selatan I Kota Lubuklinggau \\ Program Studi Sistem Informasi \\ jonikarman.mkom@gmail.com
}

\begin{abstract}
Abstrak - Sistem Informasi Kepegawaian adalah suatu system yang dikembangkan oleh pemerintah, guna mendukung system informasi pegawai negeri sipil yang terintegrasi dan akurat. SIMPEG dapat mendukung pelayanan kepegawaian salah satunya pada Badan Kepegawaian, Pendidikan dan Pelatihan Kabupaten Musi Rawas . Badan Kepegawaian, Pendidikan dan Pelatihan Kabupaten Musi Rawas sudah memiliki aplikasi SIMPEG dalam pengelolaan data pegawai tapi belum terintegrasi datanya dalam sistem berbasis WEB yang mana informasi tentang kepegawaian bisa mudah untuk didapatkan khusunya pegawai negeri sipil Kabupaten Musi Rawas. Informasi tentang kepegawaian yang dibuat oleh Badan Kepegawaian, Pendidikan dan Pelatihan Kabupaten Musi Rawas setempat menjadi sangat terbatas karena masyarakat luas tidak bias mendapatkan informasi tentang Data Pegawai Negeri Sipil sehingga perlu dibuatkan media alternatif untuk menginformasikan data pegawai agar bisa dipublikasikan masyarakat luas. SIMPEG sangat mendukung dalam pelayanan kepegawian di Badan Kepegawaian, Pendidikan dan Pelatihan Kabupaten Musi Rawas .Penelitian ini menghasilkan sebuah Sistem Informasi Pegawai berbasis web yang didalamnya terdapat Data Master Pegawai, Unit Kerja, Laporan Data Pegawai.
\end{abstract}

\section{Kata Kunci-SIMPEG,Sistem Informasi Kepegawaian,web}

\section{Pendahuluan}

Teknologi informasi sekarang ini sudah semakin berkembang, kebutuhan akan sebuah informasi yang berkualitas sangatlah diperlukan. Perkembangan teknologi banyak mempengaruhi tatanan hidup atau sebuah aturan dan sistem tertentu serta dapat dimanfaatkan dalam berbagai bidang, salah satunya yaitu dalam bidang kepegawaian. Bagi sebuah instansi pemerintah seperti Badan Kepegawaian Daerah tentunya dalam pengolahan administrasi kepegawaian yang lebih tepat, cepat, sistematis dan informative sangatlah diperlukan.

Badan Kepegawaian, Pendidikan dan Pelatihan Kabupaten Musi Rawas merupakan sebuah instansi pemerintahan yang bertugas membantu kepala daerah dalam melaksanakan manajemen Pegawai Negeri Sipil (PNS) di lingkungan Pemerintah Kabupaten Musi Rawas. Badan Kepegawaian,
Pendidikan dan Pelatihan Kabupaten Musi Rawas berfungsi menyiapkan bahan dalam perumusan kebijakan teknis dalam lingkup Kepegawaian Daerah, menyelenggarakan program kepegawaian, pengembangan dan pemberdayaan pegawai, mutasi pegawai dan penyajian informasi kepegawaian serta melakukan pengkajian dan evaluasi pengelolaan kepegawaian. Adapun tantangan yang dihadapi Badan Kepegawaian, Pendidikan dan Pelatihan Kabupaten Musi Rawas adalah menjalankan operasionalnya yaitu dalam pelaksanaan seleksi penerimaan Calon Pegawai Negeri Sipil (CPNS).

Sistem Informasi Kepegawaian sangat penting dalam memberikan pelayanan kepada seluruh personalia yang ada karena pegawai merupakan asset penting penyelenggaraan sistem pemerintahan yang perlu dikelolah dengan baik. Pengelolaan pegawai yang baik dalam lingkup kecil akan meningkatkan kinerja pegawai dan dalam lingkup yang lebih besar, akan membawa perbaikan kinerja perusahaan atau pemerintah secara keseluruhan. Mengingat perlunya pengolahan data pegawai tersebut, maka peningkatan kualitas pengolahan kepegawaian melalui implementasi Sistem Informasi Manajemen Kepegawaian merupakan salah satu prioritas. Sebagai unsur pelaksana, Badan Kepegawaian, Pendidikan dan Pelatihan Kabupaten Musi Rawas telah memiliki Sistem Informasi Kepegawaian Daerah (SIMPEG) dalam rangka meningkatkan pengelolaan administrasi kepegawaian.

\section{Metode Penelitian}

Metode Pengumpulan Data yang dilakukan dalam penelitian ini adalah dengan menggunakan Metode Studi Lapangan (Field Research), yaitu pengumpulan data melalui peninjauan secara langsung terhadap objek yang diteliti (Neuman, 2003). Metode pengumpulan data ini dapat dilakukan dengan cara : Library Research, Interview / Wawancara, Observasi.

\section{A. Pengertian Sistem Informasi}

Menurut Jogiyanto (2015:11) menyatakan bahwa " Sistem informasi adalah suatu sistem didalam suatu organisasi yang mempertemukan kebutuhan pengolahan transaksi dari suatu 
organisasi dan menyediakan pihak luar tertentu dengan laporan yang diperlukan.

Menurut Prahasta (2014:81) Sistem informasi merupakan entitas (kesatuan) formal yang terdiri dari berbagai sumber daya fisik dan logika. System informasi adalah sekumpulan komponen-komponen yang saling berhubungan dan bekerja sama untuk mengumpulkan, memproses, menyimpan dan mendistribusikan informasi terkait untuk untuk mendukung proses pengambilan keputusan, koordinasi, dan pengendalian.

\section{B. Pengertian Sistem Informasi Kepegawaian (SIMPEG)}

Berdasarkan Undang-undang Nomor 43 Tahun 1999 tentang perubahan atas Undang-undang Nomor 8 Tahun 1974 tentang Pokok-pokok Kepegawaian khususnya pasal 34 ayat (2) menyatakan perlunya penyelenggaraan dan pemeliharaan informasi kepegawaian. Untuk mendukung kebijaksanaan tersebut, dipandang perlu dibangun dan dikembangkan Sistem Informasi Manajemen Kepegawaian / Sistem Informasi Kepegawaian (SIMPEG) di limgkungan Departemen Dalam Negeri dan Pemerintah Daerah yang merupakan sub-sistem dari Sistem Informasi Manajemen Departemen Dalam Negeri (SIMDAGRI). Hal ini menjadi sangat penting dalam rangka mendukung pelaksanaan otonomi daerah dan pemberdayaan aparatur pemerintah baik di Pusat maupun Daerah sesuai esensi. Undang-undang Nomor 22 Tahun 1999 tentang Pemerintahan Daerah dan Undang-undang Nomor 25 Tahun 1999 tentang Perimbangan Keuangan antara Pusat dan Daerah.

Sementara itu, upaya untuk mendukung pemantapan administrasi kepegawaian telah dimulai dengan pembangunan Sistem Informasi Kepegawaian (SIMPEG) pada tahun 1994 di 21 Provinsi, sedangkan pengembangan selanjutnya terus dilaksanakan hingga saat ini melalui berbagai kegiatan yang meliputi :

- Pemutakhiran database pegawai serangkaian kegiatan peremajaan database kepegawaian seperti mutasi pengangkatan Pegawai Negeri Sipil, Mutasi Pangkat, Mutasi Kenaikan Gaji Berkala, Mutasi Pendidikan dan Mutasi-mutasi lainnya berdasarkan organisasi dan individu.

- Perubahan kodefikasi pada tabel induk yang meliputi tabel organisasi, tabel unit kerja, tabel wilayah, tabel pendidikan umum, dan tabel-tabel lainnya yang fleksibel sesuai dengan dinamika organisasi.

- Perubahan jenis data, elemen data dan struktur database pegawai sebagai bagian perubahan pemuktahiran database dan perubahan kodefikasi pada tabel induk.

Saat ini manajemen kepegawaian memerlukan suatu sistem perencanaan, pelaksanaan serta monitoring dan evaluasi manajemen dan administrasi kepegawaian secara cepat, akuntabel dan terintegrasi. Sistem Informasi Manajemen Kepegawaian (SIMPEG) merupakan sebuah program yang memanfaatkan teknologi yang dapat mempercepat proses pengolahan data kepegawaian sehingga dapat menunjang kelancaran administrasi kepegawaian. Secara umum Sistem Informasi Manajemen Kepegawaian dibangun dengan tujuan:

- Mewujudkan suatu Sistem Informasi Manajemen Kepegawaian yang terintegrasi dalam satu jaringan komputer, yang mampu menghasilkan informasi yang bermutu sehingga berdampak pada efektivitas organisasi.

- Mewujudkan pengelolaan manajemen kepegawaian yang efisien, efektif, terintegrasi dan akuntabel.

- Mewujudkan pelayanan administrasi kepegawaian yang cepat, mudah dan akuntabel.

Hasil yang diharapkan dari Sistem Informasi Manajemen Kepegawaian antara lain :

- Tertatanya data pegawai untuk membantu pimpinan dalam merencanakan penyebaran pegawai, dan merencanakan pelatihan pegawai di masa yang akan datang.

- Kelancaran administrasi dan manajemen kepegawaian agar pegawai mendapat hak serta melaksanakan kewajibannya dengan baik.

- Kemudahan pekerjaan di bidang administrasi dan manajemen kepegawaian dalam membuat laporan.

- Terciptanya pelaksanaan tugas yang lebih efektif dan efisien.

- Terwujudnya tertib administrasi dan tertib pengarsipan guna mendukung pelaksanaan tugas-tugas administrasi kepegawaian.

- Terbinanya tenaga-tenaga yang terampil dalam memanfaatkan teknologi informasi mutakhir dalam melaksanakan tugas-tugas administrasi kepegawaian

\section{Pengertian Web}

Menurut Peranginangin (2006:02), PHP singkatan dari Hypertext Preprocessor yang digunakan sebagai bahasa script server-side dalam pengembang web yang disisipkan pada dokumen HTML. Kelahiran PHP bermula saat Rasmus Lerdorf seorang programmer Unix dan Perl, saat sedang mencari kerja tepatnya bulan Agustus - September 1994, ia menaruh resumennya di web dan membuat skrip makro Perl CGI untuk mengetahui siapa saja yang melihat resumennya (menghitung jumlah pengunjung di dalam webnya). PHP dikenal sebagai bahasa scripting yang menyatu dengan tag HTML, dieksekusi di server, dan digunakan untuk membuat halaman web yang dinamis.

\section{Pengertian Use Case}

Menurut Shalahuddin (2013:155) Use case atau diagram use case merupakan pemodelan untuk kelakukan (behavior) sistem informasi yang akan dibuat.use case mendeskripsikan sebuah interaksi antar satu atau lebih actor dengan system informasi yang akan di buat.secara kasar,use case digunakan untuk mengetahui fungsi apa saja yang ada di dalam sebuah system informasi dan siapa saja berhak menggunakan fungsifungsi itu.Syarat penamaan pada use case adalah nama didefinisikan sesimple mungkin dan dapat dipahami.ada dua hal utama pada use case yaitu pendefinisian apa yang di sebut aktor dan use case.

\section{HASIL DAN PEMBAHASAN}

\section{A. Analisa Sistem}

\section{1) Analisa Sistem Yang Berjalan}


Sistem informasi kepegawaian Kabupaten Musirawas pada saat ini sudah tersedia, namun berupa aplikasi offline sehingga masyarakat dan pemerintah untuk mencari informasi kepegawaian Kabupaten Musirawas mengalami kendala karena tidak tersedia secara online. Maka tidaklah menjadi heran jika masyarakat dalam mencari apapun menggunakan internet termasuk juga dalam mencari informasi kepegawaian Kabupaten Musirawas. Sistem informasi kepegawaian Kabupaten Musirawas ini menawarkan solusi dengan menampilakan informasi data master pegawai , mengelola data unit kerja, mengelola data mutasi, dan mengelola data pensiun/meninggal.

\section{2) Alternatif Pemecahan Masalah}

Sistem informasi kepegawaian Kabupaten Musirawas merupakan Sistem Informasi yang didukung dengan perangkat komputer dan program aplikasi sehingga penampilan informasi tentang data kepegawaian akan lebih mudah dan dalam pencarian informasipun tentunya tidak memerlukan waktu yang lama, dimana pada aplikasi ini menggunakan bahasa pemograman PHP dan MySQL yang menawarkan begitu banyak kemudahan dalam merancang sebuah program.

\section{B. Perancangan Sistem}

1) Perancangan Dengan Menggunakan UML (Unified Modeling Language)

a) Use Case Diagram

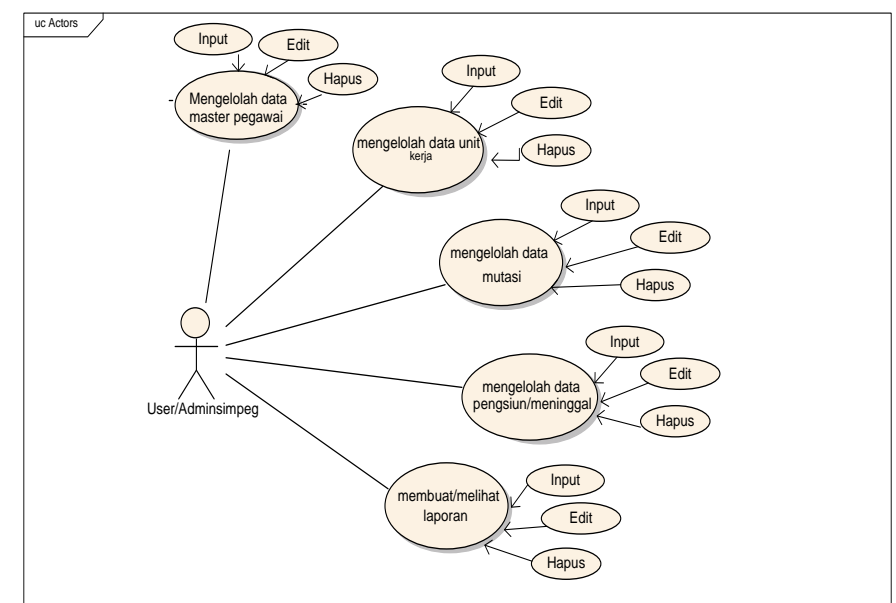

Gambar 1. Use Case Diagram SIMPEG Musirawas

\section{2) Kebutuhan Fungsional Sistem}

Arsitektur sistem disini dapat digambarkan dengan class diagram, dimana class adalah sebuah spesifikasi yang menghasilkan sebuah objek dan merupakan inti dari pengembangan dan desain berorientasi objek. Class Diagram mengggambarkan keadaan (atribut/property) suatu sistem, sekaligus menawarkan layanan untuk memanipulasi keadaan tersebut (metode/fungsi). Class Diagram ini berisikan objek-objek yang terdapat didalam Sistem Informasi Kepegawaian Daerah Kabupaten Musirawas berbasis web.

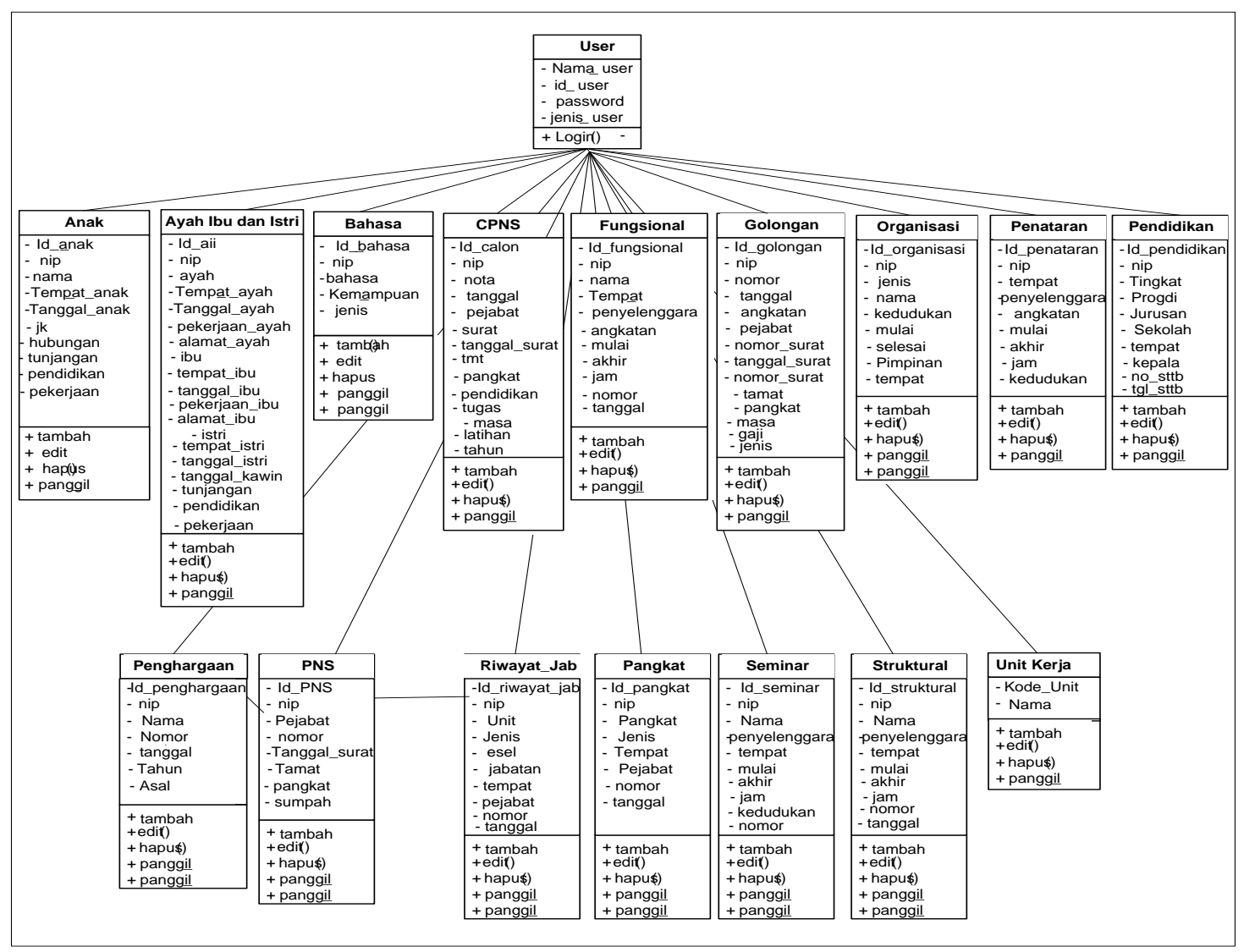

Gambar 2. Class Diagram SIMPEG Musirawas 


\section{Pembahasan}

\section{1) Halaman Menu Utama SIMPEG}

Sistem informasi kepegawaian ini memiliki banyak menu, baik menu input maupun menu daftar data. Selain itu juga sistem informasi kepegawaian ini memilki menu laporan sebgai acuan dalam pembuatan laporan. Berikut adalah tampilan halaman utama yang menampilkan masing-masing menu tersebut. Tampilan menu utama dapat dilihat pada gambar 3 .

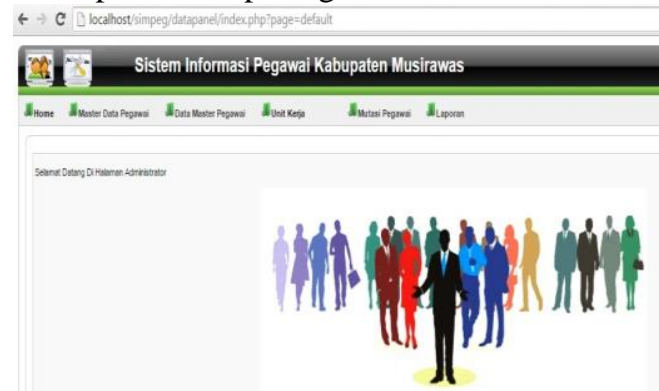

Gambar 3. Tampilan Halaman Menu Utama SIMPEG

\section{2) Halaman Menu Identitas Pegawai}

Menu master pegawai terdiri dari beberapa sub menu. Berikut adalah salah satu penjelasan dari masing masing tampilan dari sub menu tersebut.

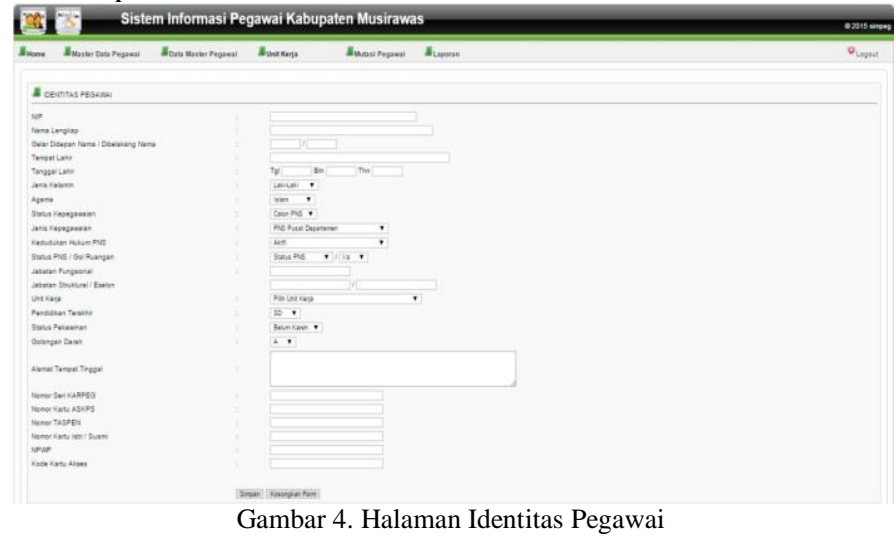

\section{3) Halaman SubMenu Calon PNS}

Halaman Sub menu calon PNS digunakan sebagai media untuk melakukan input data pegawai sebagai calon PNS pegawai. Berikut adalah tampilan dari form input calon PNS.

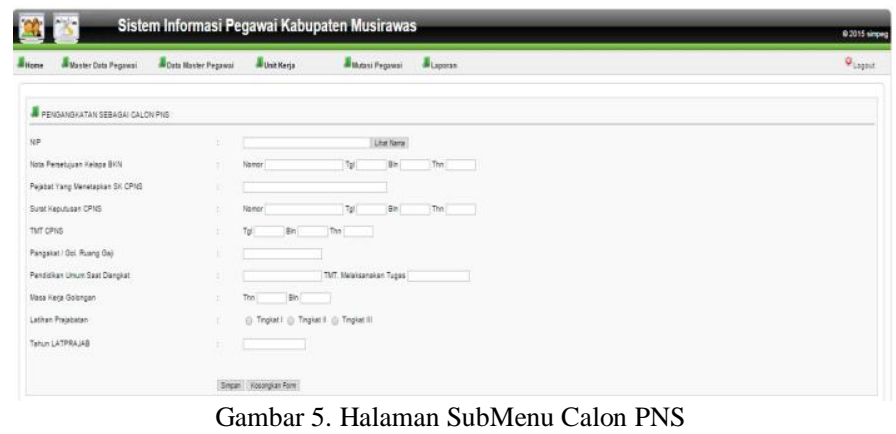

\section{4) Halaman SubMenu PNS}

Sub menu sebagai PNS digunakan sebagai media untuk melakukan input data pegawai ketika diangkat menjadi PNS. Berikut adalah tampilan dari form input pegawai sebagai PNS.

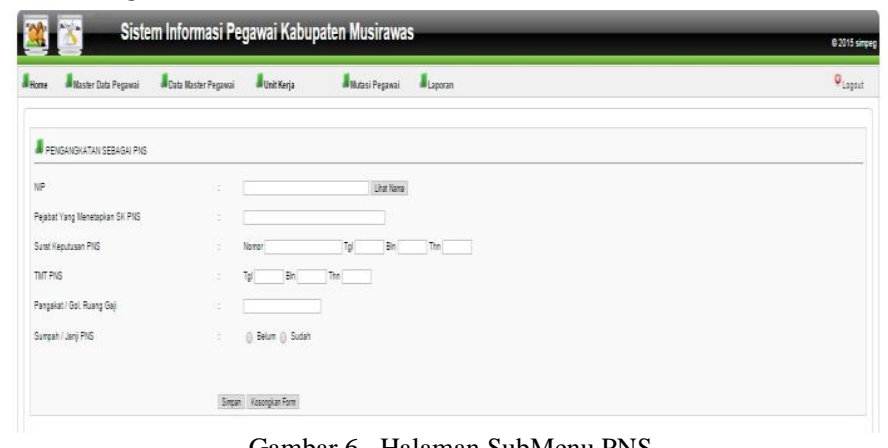

Gambar 6. Halaman SubMenu PNS

5) Halaman Menu Diklat, Penataran, Seminar dan Kursus Sub menu diklat, penataran, seminar dan kursus digunakan sebagai media untuk melakukan input data diklat, penataran, seminar dan kursus yang diikuti oleh pegawai. Berikut adalah tampilan dari form input diklat, penataran, seminar dan kursus.

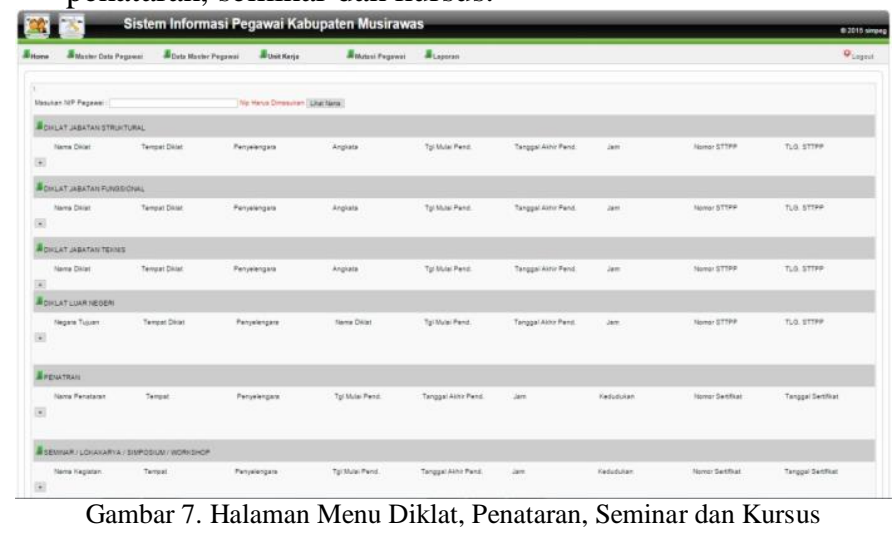

\section{6) Halaman Menu Unit Kerja}

Menu umit kerja digunakan sebagai media untuk melakukan pengelolaan data unit kerja atau Satuan Kerja Perangkat Daerah (SKPD) pegawai. Berikut adalah tampilan dari halaman menu unit kerja.

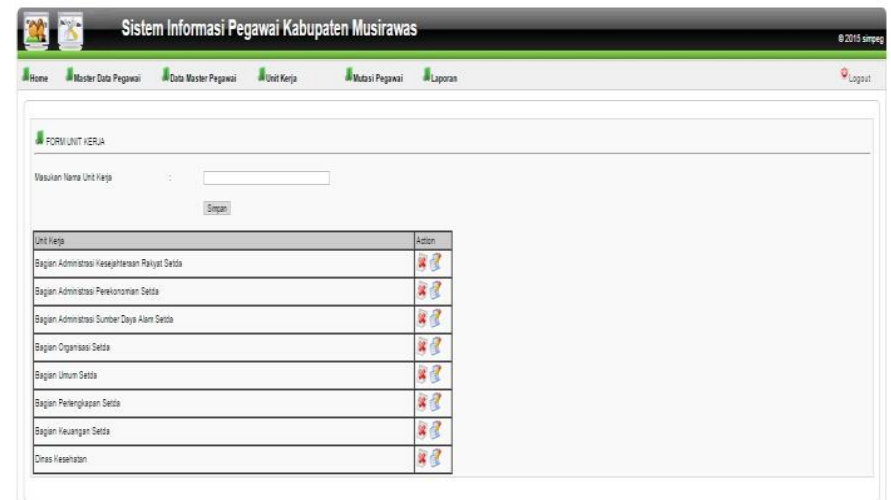

Gambar 8. Halaman Menu Unit Kerja 


\section{7) Halaman Menu Meninggal/Pengsiun}

Menu meninggal atau pengsiun adalah menu yang digunakan untuk memproses pegawai yang telah meninggal atau pengsiun. Proses tersebut diproses jika pegawai telah meninggal dunia atau pengsiun dari kepegawaian daerah Kabupaten Musirawas. Berikut adalah tampilan dari halaman menginggal atau pengsiun.

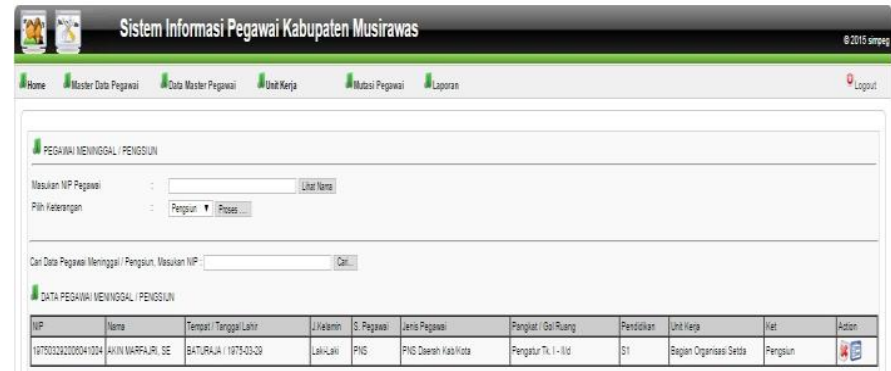

Gambar 9. Halaman Menu Unit Kerja

\section{8) Halaman Menu Laporan Berdasarkan Unit Kerja}

Laporan pegawai berdasarkan unit kerja menampilkan laporan jumlah pegawai pada masing-masing unit kerja yang ada pada Kabupaten Musirawas. Berikut adalah tampilan dari laporan pegawai berdasarkan unit kerja.

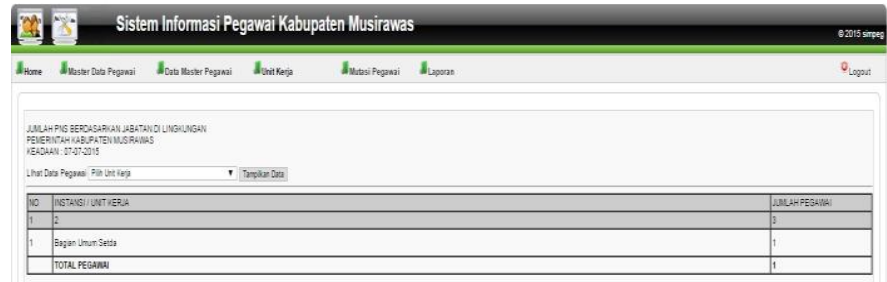

Gambar 10. Halaman Menu Laporan Berdasarkan Unit Kerja

9) Halaman Menu Laporan Berdasarkan Jabatan Fungsional

Laporan pegawai berdasarkan jabatan fungsional menampilkan laporan jumlah pegawai berdasarkan jabatan fungsional yang ada pada Kabupaten Musirawas. Berikut adalah tampilan dari laporan pegawai berdasarkan jabatan fungsional.

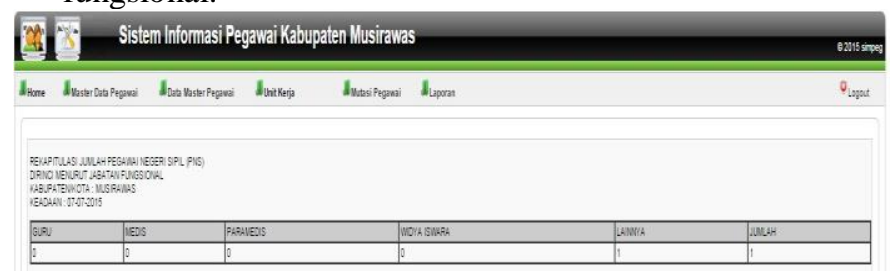

Gambar 11. Halaman Menu Laporan Berdasarkan Jabatan Fungsional
10) Halaman Menu Laporan Berdasarkan Usia dan Jenis Kelamin

Laporan pegawai berdasarkan usia dan jenis kelamin menampilkan laporan jumlah pegawai berdasarkan usia dan jenis kelamin yang ada pada Kabupaten Musirawas. Berikut adalah tampilan dari laporan pegawai berdasarkan usia dan jenis kelamin.

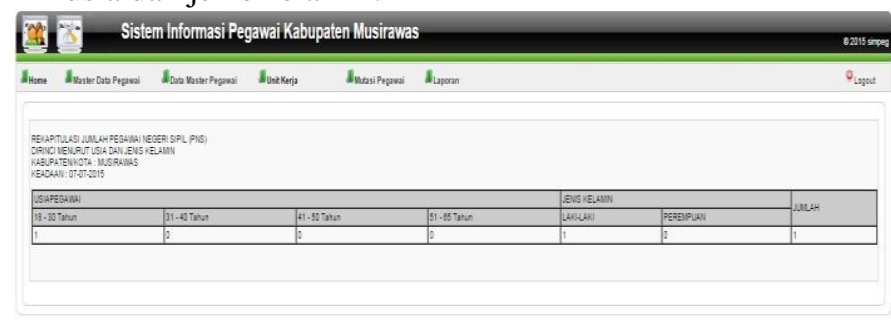

Gambar 12. Halaman Menu Laporan Berdasarkan Usia dan Jenis Kelamin

\section{1) Halaman Menu Laporan Berdasarkan Golongan}

Halaman menu laporan berdasarkan golongan yaitu untuk membuat laporan pegawai berdasarkan golongan. Halaman menu laporan berdasarkan golongan dapat dilihat pada gambar 13 .

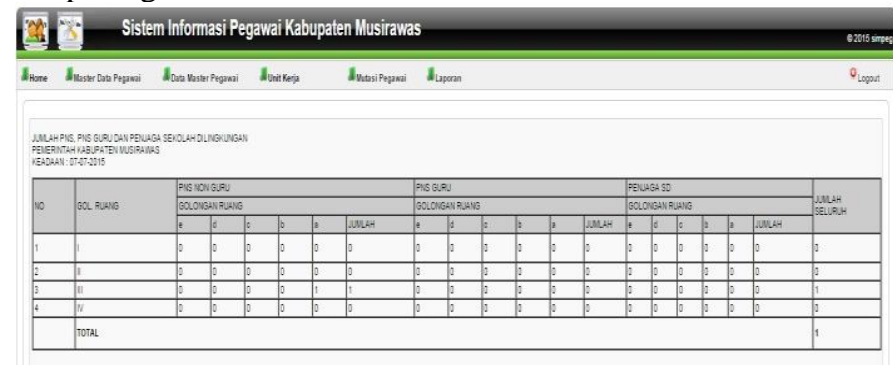

Gambar 13. Halaman Menu Laporan Berdasarkan Golongan

\section{PenUtuP}

\section{A. Kesimpulan}

Dari hasil penelitian yang telah dilakukan terhadap penelitian ini dapat diambil kesimpulan sebagai berikut :

- Sistem informasi kepegawaian Kabupaten Musirawas dapat menampilkan informasi tentang data pegawai secara efektif dan efisien dengan menggunakan aplikasi web editor Adobe Dreamweaver CS6 dan bahasa pemograman PHP dan MySQL sebagai database yang menghasilkan suatu informasi yang cepat, tepat, dan akurat.

- Sistem informasi kepegawaian Kabupaten Musi Rawas dapat menampilkan laporan berupa data pegawai berdasarkan SKPD/Unit kerja, klasifikasi sekolah, jabatan fungsional, usia dan jenis kelamin, jenis kelamin dan pendidikan serta berdasarkan golongan ruang. 


\section{B. Saran}

Dari hasil penelitian yang dilakukan dapat dikemukakan beberapa saran yang diharapkan dapat menjadi bahan pertimbangan lebih lanjut dalam upaya peningkatan pengolahan data dalam Sistem informasi kepegawaian Kabupaten Musirawas. Adapun saran - saran yang dianggap perlu yaitu :

- Sistem informasi kepegawaian Kabupaten Musirawas hendaknya menggunakan data terbaru sehingga informasi yang ada selalu akurat.

- Untuk penelitian lebih lanjut, peneliti menyarankan agar pemanfaatan teknologi informasi dapat dilakukan secara maksimal oleh terutama pemanfaatan Sistem informasi kepegawaian Kabupaten Musirawas. Diharapkan dapat menjadi salah satu inspirasi bagi Kabupaten Musirawas Khususnya untuk melengkapi aplikasi yang ada dan dapat dikembangkan menjadi salah satu system informasi yang handal serta dapat menjadi inspirasi bagi lembaga ataupun instansi yang lain.

\section{DAFTAR PUSTAKA}

[1] Anonim, 2000. Sistem Informasi Manajemen Kepegawaian Departemen Dalam Negeri dan Pemerintah Daerah, http://www.depdagri.go.id/produk-hukum/2000/05/30/keputusanmendagri-no-17-tahun-2000, http://www.depdagri.go.id/produk-hukum2000/05/30/keputusan-mendagri-no-17-tahun-2000-lamp, diakses tanggal 2 Februari 2015

[2] Jogiyanto, HM. 2005. Analisis dan Desain Sistem Informasi Pendekatan Terstruktur Teori dan Praktik Aplikasi Bisnis, Penerbit Andi, Yogyakarta.

[3] Peranginangin, Kasiman, 2006. Aplikasi Web Dengan PHP Dan MySQL, Andi Yogyakarta.

[4] Prahasta, Edi, 2014 . "Konsep-Konsep Dasar : Sistem Informasi Geografis". Informatika. Bandung.

[5] Septyana, Nanda. Naskah Publikasi Sistem Informasi Kepegawaian Pada Dinas Perhubungan Komunikasi dan Informatika Kabupaten Cilacap, 2011

[6] Rosa , AS \& Shalahuddin ,2013. "Rekayasa Perangkat Lunak" Bandung : Informatika. 